\title{
ЦЕНТРОБЕЖНЫЕ ТЕНДЕНЦИИ В США: ИСТОРИЯ И СОВРЕМЕННОСТЬ. ЭКОНОМИЧЕСКИЙ АСПЕКТ
}

\author{
(C) 2020 Фадеева Инна Авенировна \\ кандидат экономических наук, профессор \\ Дипломатическая академия Министерства иностранных дел Российской Федерации, \\ Россия, Москва \\ E-mail: innaf576@mail.ru
}

Целью статьи является анализ экономических предпосылок возникновения дезинтеграционных процессов на территории США. Для достижения данной цели решены задачи: уточнения содержания понятия «дезинтеграционные процессы»; оценка экономической ситуации в США как результата введенных в условиях пандемии нового коронавируса массовых ограничений; авторские оценки перспектив центробежных тенденций в США в новых экономических условиях. В статье подчеркивается необходимость расширенного понимания термина «дезинтеграционные процессы» в теории международной экономической интеграции. Сделан вывод, что рассмотрение дезинтеграционных процессов только как вектора, направленного на распад экономических систем - не позволяет провести анализ скрытых дезинтеграционных течений и предпосылок в некоторых системах. В статье проведен анализ некоторых экономических последствий масштабных ограничений в условиях пандемии коронавируса и их влияния на экономику США. Установлено, что глубокое падение экономики США и прогнозы ее развития в ближнесрочный период свидетельствуют о наличии предпосылок для ускорения неявных дезинтеграционных процессов на территории страны. В статье делается вывод о том, что экономические последствия пандемии нового коронавируса становятся вызовом не только для интеграционных объединений, но и стран, в которых будут усиливаться противоречия между регионами и центром. Таким образом, в последний год появляются новые экономические условия для ускорения центробежных тенденций в США.

Ключевые слова: дезинтеграционные процессы, дезинтеграционные проявления, США, центробежные тенденции, пандемия, COVID-19

В отличии от теории международной экономической интеграции, ее составляющая часть - теория международной экономической дезинтеграции - развита в гораздо меньшей степени. В нынешних условиях ввиду ускорения дезинтеграционных процессов требуется научное осмысление комплекса причин и факторов данных процессов, хода их течения, типологии и прочих аспектов всей системы дезинтеграционных проявлений. Современные исследователи, анализируя ход интеграционных процессов нового столетия и их тенденции, верно отмечают их трансформацию, увеличение количества дезинтеграционных проявлений в самых различных формах: «последние два десятилетия характеризовались значительным ускорением международной экономической интеграции как на глобальном, так и на региональном уровнях. Государства повсеместно ограничивали национальные суверенитеты, надеясь на обеспечение стабильности и предсказуемости экономическо- го роста. Но такая модель международной экономической интеграции привела к тревожным признакам дезинтеграции. Распад проявляется в международно-правовом-аспекте, международном экономическом порядке, в виде других дезинтеграционных проявлений - социальных, экономических, экологических, обусловленных такими ограничениями национальных суверенитетов. Такая модель экономических отношений влечет за собой значительное множество скрытых издержек для общества» [1].

В одном из влиятельных изданий «Откровенный разговор о торговле», Д.Родрик убедительно критикует существующий международный экономический порядок, заключая, что «Итак, я согласен с тем, что национальные государства являются источником дезинтеграции мировой экономики» [2]. Таким образом, автор делает вывод, что национальные государства сами по себе становятся источниками дезинтеграционных процессов в новом международном 
экономическом порядке, поскольку уделяют особо внимание к торговым и инвестиционным соглашениям.

Отсутствие комплексных исследований, посвященных данной проблеме, приводит к некорректным представлениям о некоторых сторонах теории и практики дезинтеграционных процессов. Например, в гораздо большей степени распространено мнение о тождестве дезинтеграционных процессов и процессов распада интеграционных объединений [3]. Однако распад интеграционного объединения - только последняя, самая острая стадия дезинтеграционного процесса и наиболее тяжелое для интеграционного объединения дезинтеграционного проявления. Корректней рассматривать дезинтеграционные процессы только как общее ослабление экономических связей и такая позиция представлена в некоторых исследованиях [4].

Рассмотрение дезинтеграционных процессов только как вектора, направленного на распад экономических систем - не позволяет провести анализ скрытых дезинтеграционных течений и предпосылок в некоторых системах. К примеру, в ряде крупных стран, объединяющих регионы с различным уровнем социально-экономического развития (Китай [5], США [6], Испания [7]), а также интеграционных объединениях - ЕС [8], ЕАЭС [9], ШОС [10], БРИКС [11] и других.

Соединенные Штаты Америки - государство, развитие которого долгие годы характеризуется наличием неявных дезинтеграционных проявлений. Значение США для мировой экономики тре- бует анализа отдельных экономических аспектов дезинтеграционных проявлений в США.

Долгие годы США находится в числе лидеров мировой экономики. Благоприятная динамика ключевых макроэкономических показателей в США (таблица 1) [12] в последние годы являлась фактором, снижающим возможность ускорения течения неявных дезинтеграционных процессов.

В 2020 году ввиду массовых экономических ограничений, введенных для снижения негативных последствий пандемии нового коронавируса, ситуация существенно изменилась, что может способствовать усилению региональной неоднородности и развитию дезинтеграционных проявлений. США стала одной из самых пострадавших от пандемии нового коронавируса стран - по данным на октябрь 2020 года в стране регистрировалось до 85 тыс. новых случаев заболевания в день; общее количество заболевших составило почти 9 млн. человек [13].

По данным Бюро экономического анализа Министерства торговли США, по итогам второго квартала 2020 года, окончание которого совпало с первой волной распространения эпидемии коронавируса, ВВП страны сократился на 32,9\% относительно предыдущего квартала 2020 года (рисунок 1) [14]. Это наиболее глубокое квартальное падение ключевого макроэкономического показателя страны за все годы наблюдений. Значительно снизился во втором квартале 2020 года и объем импорта товаров и услуг (на 53,4\%), экспорта товаров и услуг (на 64,1\%), а также ряд других показателей.

Таблица 1. Динамика макроэкономических показателей США, 2000-2019 годы

\begin{tabular}{|l|c|c|c|c|c|c|c|c|}
\hline \multicolumn{1}{|c|}{ Показатель } & 2000 & 2005 & 2010 & 2015 & 2016 & 2017 & 2018 & 2019 \\
\hline ВВП в текущих ценах, трлн. долл. & 10,3 & 13,0 & 15,0 & 18,2 & 18,7 & 19,5 & 20,5 & 21,4 \\
\hline в \% от мирового ВВП в текущих ценах & 30,5 & 27,4 & 22,7 & 24,2 & 24,5 & 24,0 & 23,8 & 24,4 \\
\hline $\begin{array}{l}\text { темпы прироста (снижения) ВВП в \% к } \\
\text { предыдущему году }\end{array}$ & 4,1 & 3,5 & 2,6 & 2,9 & 1,6 & 2,2 & 2,9 & 2,3 \\
\hline ВВП на душу населения, тыс. долл. & 36,3 & 44,1 & 48,5 & 56,8 & 57,9 & 60,0 & 62,8 & 65,1 \\
\hline $\begin{array}{l}\text { Отношение ВВП на душу населения в } \\
\text { США к ВВП на душу населения по всем } \\
\text { странам мира, раз }\end{array}$ & 6,6 & 6,0 & 5,1 & 5,5 & 5,6 & 5,5 & 5,5 & 5,7 \\
\hline $\begin{array}{l}\text { темпы прироста (снижения) ВВП на } \\
\text { душу населения в \% к предыдущему } \\
\text { году }\end{array}$ & 3,0 & 2,6 & 1,7 & 2,1 & 0,8 & 1,6 & 2,4 & 1,8 \\
\hline Экспорт товаров и услуг, в \% к ВВП & 10,7 & 10,0 & 12,3 & 12,4 & 11,9 & 12,1 & 12,2 & 11,7 \\
\hline $\begin{array}{l}\text { Темпы прироста экспорта товаров и } \\
\text { услуг в \% к предыдущему году }\end{array}$ & 8,3 & 7,1 & 12,1 & 0,5 & 0,0 & 3,5 & 3,0 & 3,4 \\
\hline Импорт товаров и услуг, в\% к ВВП & 14,4 & 15,5 & 15,7 & 15,3 & 14,6 & 15,0 & 15,3 & 14,7 \\
\hline $\begin{array}{l}\text { Темпы прироста импорта товаров и } \\
\text { услуг в \% к предыдущему году }\end{array}$ & 12,9 & 6,5 & 13,1 & 5,3 & 2,0 & 4,7 & 4,4 & 4,5 \\
\hline
\end{tabular}

Источник: составлено на основе данных Всемирного Банка 


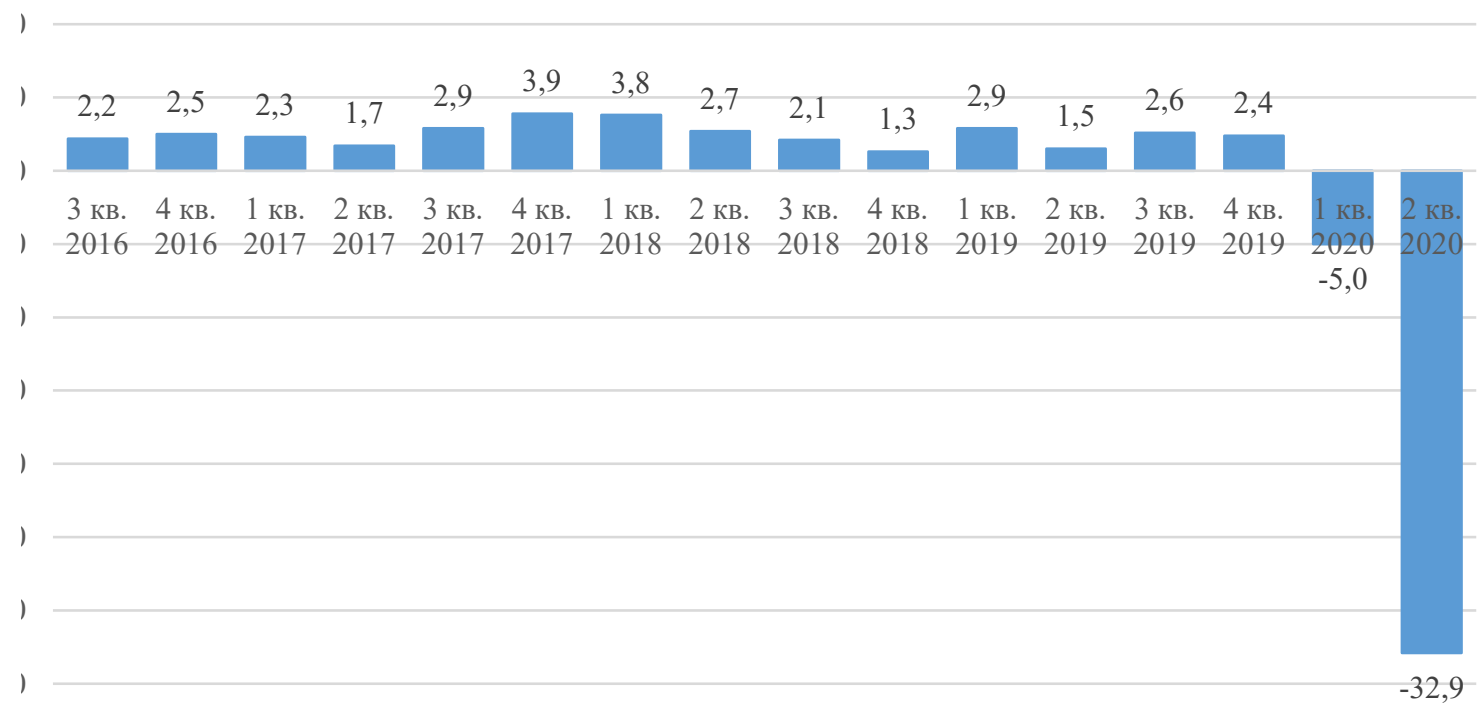

Рисунок 1. Квартальные значения динамики ВВП США за 2016-2020 годы Источник: на основе данных Бюро экономического анализа Министерства торговли США

Согласно базовому прогнозу Conference Board, к 2021 году следует ожидать небольшого роста экономики США на 3,5\%; оптимистичному прогнозу - на 7,1\% и пессимистичному - на $1,0 \%$ [15]. Согласно прогнозу представителей Deloitte, в базовом сценарии следует ожидать снижения ВВП США в 2021 году на 1,7\% с дальнейшим восстановлением; в случае выделения поддержки центральными властями - рост ВВП на 2,5\% в 2021 году; и в ситуации, если динамика заражений не улучшится - падение ВВП в 2021 году на 3,8\% с дальнейшим восстановлением [16].

Риски для экономики США непременно скажутся на региональном развитии. Среди угроз для регионального развития, способных спровоцировать центробежные тенденции, можно выделить:

- усиление экономической неоднородности регионального развития;

- усиление социальной неоднородности в региональном развитии;

- смещение «центров экономической тяжести» от одних штатов к другим.

Негативная экономическая обстановка обусловила различную глубину падения ВРП штатов США (таблица 2) [17].

Таким образом, пандемия коронавируса и ее последствия в США создают экономические условия для ослабления связей или дезинтеграционных проявлений в стране. Надо отметить, что дезинтеграционные проявления в США, в том числе сецессионные устремления отдельных ре- гионов имеют место уже долгие годы и проявляли себя на современном этапе развития страны.

Например, в 1861 году такие штаты как Южная Каролина, Миссисипи, Флорида, Алабама, Джорджия, Луизиана и Техас потребовали суверенитета, образовав 4 февраля этого же года Конфедеративные Штаты Америки [18]. Суть требований штатов состояла в возврате полномочий, делегированных по Конституции 1787 года федеральному правительству. Новое образование прекратило свое существование после Гражданской войны 1861-1865 годов.

В современное время - в 2009 году - губернатором штата Техас Р.Перри была объявлена возможность появления нового суверенного политического образования [19]. Проведенный опрос показал, что только четверть жителей штата согласны с таким сецессионным устремлением.

Дезинтеграционные проявления наблюдались и в 2012 году, когда было обнародовано несколько петиций и собраны десятки тысяч подписей о выходе отдельных штатов из США. Хотя такие акции не имели правового значения, они также свидетельствуют о наличии неявных дезинтеграционных проявлений в стране [20].

Подводя итог, можно отметить, что дезинтеграционные проявления, как правило, характерны для периодов экономической нестабильности. В эти периоды наблюдается усиление неравномерности территориального экономического развития в интеграционных объедине- 
Таблица 2. Динамика ВРП в первом и втором квартале 2020 года по штатам США

\begin{tabular}{|c|c|c|}
\hline Штат & 1 кв. 2020 & 2 кв. 2020 \\
\hline Гавайи & $-8,9$ & $-42,2$ \\
\hline Невада & $-4,9$ & $-42,2$ \\
\hline Теннесси & $-3,9$ & $-40,4$ \\
\hline Вермонт & $-5,8$ & $-38,2$ \\
\hline Мичиган & $-7,9$ & $-37,6$ \\
\hline Нью-Гемпшир & $-2,2$ & $-36,9$ \\
\hline Нью-Йорк & $-6,2$ & $-36,3$ \\
\hline Нью-Джерси & $-3,3$ & $-35,6$ \\
\hline Кентукки & $-5,0$ & $-34,5$ \\
\hline Мэн & $-6,5$ & $-34,4$ \\
\hline Пенсильвания & $-5,8$ & $-34,0$ \\
\hline Аляска & $-6,0$ & $-33,8$ \\
\hline Индиана & $-5,2$ & $-33,0$ \\
\hline Огайо & $-5,6$ & $-33,0$ \\
\hline Миссисипи & $-3,7$ & $-32,9$ \\
\hline Висконсин & $-8,8$ & $-32,6$ \\
\hline Южная Каролина & $-8,2$ & $-32,6$ \\
\hline Вайоминг & $-10,5$ & $-32,5$ \\
\hline Род-Айленд & $-5,2$ & $-32,4$ \\
\hline Айдахо & $-1,9$ & $-32,4$ \\
\hline Миссури & $-5,1$ & $-32,1$ \\
\hline Орегон & $-4,0$ & $-31,9$ \\
\hline Массачусетс & $-4,3$ & $-31,6$ \\
\hline Калифорния & $-4,3$ & $-31,5$ \\
\hline Луизиана & $-11,9$ & $-31,4$ \\
\hline Миннесота & $-6,8$ & $-31,3$ \\
\hline Коннектикут & $-6,0$ & $-31,1$ \\
\hline Оклахома & $-7,3$ & $-31,1$ \\
\hline Небраска & $-3,4$ & $-31,0$ \\
\hline Монтана & $-4,8$ & $-30,8$ \\
\hline Северная Каролина & $-3,5$ & $-30,5$ \\
\hline Канзас & $-3,5$ & $-30,3$ \\
\hline Флорида & $-4,3$ & $-30,1$ \\
\hline Иллинойс & $-6,3$ & $-29,7$ \\
\hline Алабама & $-3,2$ & $-29,6$ \\
\hline западная Вирджиния & $-6,7$ & $-29,6$ \\
\hline Texac & $-6,2$ & $-29,0$ \\
\hline Северная Дакота & $-2,4$ & $-28,8$ \\
\hline Нью-Мексико & $-4,7$ & $-28,3$ \\
\hline Айова & $-2,0$ & $-28,2$ \\
\hline Колорадо & $-1,3$ & $-28,1$ \\
\hline Арканзас & $-4,0$ & $-27,9$ \\
\hline Мэриленд & $-3,6$ & $-27,7$ \\
\hline Грузия & $-4,0$ & $-27,7$ \\
\hline Северная Дакота & $-1,6$ & $-27,6$ \\
\hline Вирджиния & $-5,0$ & $-27,0$ \\
\hline Вашингтон & $-2,6$ & $-25,5$ \\
\hline Аризона & $-3,2$ & $-25,3$ \\
\hline Юта & $-3,9$ & $-22,4$ \\
\hline Делавэр & $-11,4$ & $-21,9$ \\
\hline
\end{tabular}


ниях и крупных странах федеративного типа государственного устройства. Экономические последствия пандемии нового коронавируса становятся вызовом не только для интеграционных объединений, но и стран, в которых будут усиливаться противоречия между регионами и центром. Таким образом, в последний год появляются новые экономические условия для ускорения центробежных тенденций в США.

\section{Библиографический список}

1. Montanaro, F., \& Violi, F. (2020). The Remains of the Day: The International Economic Order in the Era of Disintegration*. Journal of International Economic Law, 23(2), 299-322. Available at SSRN: https://ssrn.com/ abstract $=3680567$

2. Dani Rodrik Straight Talk on Trade Princeton University Press, Princeton, NJ, 2017, 336 pp.

3. Галичкин A.E. Анализ центробежных и центростремительных тенденций в процессе глобализации // Экономика и предпринимательство. 2015. № 10-1 (63). С. 190-193.; Obstfeld, M. (2020). Globalization Cycles. Italian Economic Journal, 6(1). DOI: 10.1007/s40797-020-00121-4; Sampson, T. (2017). Brexit: The economics of international disintegration. Journal of Economic Perspectives, 31(4), 163-184. URL: https://personal.lse.ac.uk/ sampsont/BrexitDisintegration.pdf (дата обращения: 12.10.2020).

4. Воронина Т.В. Международная экономическая интеграция: императивы, противоречия, тенденции развития: дис. ... д-ра экон. наук. Ростов-на-Дону, 2013. с. 117.; Раковская-Самойлова А.Х. К вопросу об интеграционных и дезинтеграционных процессах в экономике // Экономика развития. 2012. № 4 (64). С. 36-40.

5. Васильев Л.Е. О Некоторых аспектах борьбы Китая с силами «трех зол» // Китай в мировой и региональной политике. История и современность. 2018. Т. 23. № 23. С. 92-106.; Clarke, M. (2013). Ethnic Separatism in the People's Republic of China History, Causes and Contemporary Challenges. European Journal of East Asian Studies, 12(1), 109-133. https://doi.org/10.1163/15700615-13120108

6. Панарин И. Н. Крах доллара и распад США 2.0. Москва: Горячая линия-Телеком, 2019. 391 с.

7. Хенкин С. М. Каталонский конфликт: национальное и международное измерения // Актуальные проблемы Европы. 2020. № 2 (106). С. 94-121.

8. Arnorsson, A., \& Zoega, G. (2018). On the causes of Brexit. European Journal of Political Economy, 55, 301-323. DOI: 10.1016/j.ejpoleco.2018.02.001

9. Фадеева И.А. ЕАЭС: дезинтеграционные тренды интеграционного проекта // Экономика и предпринимательство. 2017. № 5-1 (82). С. 1102-1105.

10. Фадеева И. А. Дезинтеграционные проявления в ШОС и их влияние на экономическое развитие государствчленов интеграции // Экономика и предпринимательство. 2019. № 10 (111). С. 212-215.

11. Фадеева И.А.Дезинтеграционные проявления в странах брикс: предпосылки и экономические последствия для группировки // Kant. 2020. № 1 (34). С. 102-106.

12. World Bank Open Data // The World Bank. URL: https://data.worldbank.org (дата обращения: 02.10.2020).

13. Coronavirus Cases. United States // Worldometer. URL: https://www.worldometers.info/coronavirus/country/us/ (дата обращения: 16.10.2020).

14. News Release // BEA. URL: https://www.bea.gov/news/2020/gross-domestic-product-2nd-quarter-2020-advanceestimate-and-annual-update (дата обращения: 21.10.2020).

15. The Conference Board Economic Forecast for the US Economy // The Conference Board. URL: https://www. conference-board.org/research/us-forecast (дата обращения: 19.10.2020).

16. United States Economic Forecast / Deloitte. URL: https://www2.deloitte.com/us/en/insights/economy/useconomic-forecast/united-states-outlook-analysis.html (дата обращения: 21.10.2020).

17. Gross Domestic Product by State, 2nd Quarter 2020 // BEA. URL: https://www.bea.gov/news/2020/gross-domesticproduct-state-2nd-quarter-2020 (дата обращения: 21.10.2020).

18. Гончарова K.А.Война между севером и югом: причины, этапы и её государственно-правовые последствия для США // Аллея науки. 2019. Т. 1. № 5 (32). С. 607-610.; Чечелев С. В. Политический режим Конфедеративных Штатов Америки // Вестник Омского университета. Серия: Право. 2016. № 4 (49). С. 24-25.; Powell M.A. The conscription act of April 1862 as a constitutional challenge in the confederate revolution. Vestnik of Saint Petersburg University. History, 2017, vol. 62, issue 3, pp. 613-626.

19. Rick Perry’s passion for states' rights // The Washington Post. URL: https://www.washingtonpost.com/opinions/ rick-perrys-passion-for-states-rights/2011/07/25/gIQAWa2WZI_story.html (дата обращения: 21.10.2020). 
20. White House receives secession pleas from all 50 states // The Los Angeles Times. URL: https://www.latimes.com/ politics/la-xpm-2012-nov-14-la-pn-white-house-secession-50-states-20121114-story.html (дата обращения: 14.10.2020); White House Rejects Petitions to Secede, but Texans Fight On // The New York Times. URL: https:// www.nytimes.com/2013/01/16/us/politics/texas-secession-movement-unbowed-by-white-house-rejection.html (дата обращения: 14.10.2020). 